Tarih Kültür ve Sanat Araştırmaları Dergisi

Revue des Recherches en Histoire Culture et Art مجلة البحوث التاريخبة و الثقافية والفنية
Vol. 7, No. 4, November 2018

Copyright (C) Karabuk University http://kutaksam.karabuk.edu.tr

\title{
DOI: 10.7596/taksad.v7i4.1867
}

Citation: Druzhinina, V., Shubina, N., Akinina, N., \& Lazutkina, O. (2018). The Problem of Social and Professional Adaptation of University Graduates in Higher Education Development. Journal of History Culture and Art Research, 7(4), 435-441. doi:http://dx.doi.org/10.7596/taksad.v7i4.1867

\section{The Problem of Social and Professional Adaptation of University Graduates in Higher Education Development}

\author{
Vera Druzhinina1, Natalia Shubina², \\ Natalia Akinina ${ }^{3}$, Olesya Lazutkina ${ }^{4}$
}

\begin{abstract}
Some problems of socialization of youth in the conditions of transformation of the social and economic relations, crisis situations in various spheres of life of society have been studied in the paper. The socioeconomic conditions of modern Russian society defining bachelors' professional socialization have been investigated. Domestic researches of graduates' social and professional adaptation have been analyzed. Main difficulties which university graduates meet in the course of professional social adaptation have been revealed. The attention on social institute of professional education exerting a great influence on process of socialization of an individual has been focused. Professional focused training in higher education institution; technologies creating imitating actions during the educational or work practice of students have been presented as a condition of reduction of professional adaptation terms. The authors pay attention to the question of university graduate's employment which is one of criteria of overall performance on bachelor's training for modern high school education and, at the same time, starts process of adaptation of a university graduate to modern conditions of labor market which result will be a mastering professional and personal qualities for increase in competitiveness in constantly changing production conditions. The great value to ability to adapt quickly to variability of social living conditions, ability to react flexibly to modern calls in the conditions of work and public life of society have been emphasized.
\end{abstract}

Keywords: Professionalism, Professional socialization, Socialization of the individual, Professional and social adaptation, Competitive growth.

\footnotetext{
1 PhD in Philology, associate professor, Stary Oskol branch Belgorod State University 18, Solnechny microdistrict, Stary Oskol, Belgorod region, 309502, Russia. E-mail: admin@sof.bsu.edu.ru

$2 \mathrm{PhD}$ in Philology, associate professor, Stary Oskol branch Belgorod State University 18, Solnechny microdistrict, Stary Oskol, Belgorod region, 309502, Russia. E-mail: Shubina@bsu.edu.ru

3 PhD in Pedagogy, associate professor, Stary Oskol branch Belgorod State University 18, Solnechny microdistrict, Stary Oskol, Belgorod region, 309502, Russia. E-mail: akinina@bsu.edu.ru

${ }^{4} \mathrm{PhD}$ in Philology, senior lector, Belgorod National Research University, 85, Pobeda Street, Belgorod, 308015, Russia. E-mail: Info@bsu.edu.ru
} 


\section{Introduction}

The modern context of the development of higher education is connected with the world in a state of globalization in all spheres of human life, whether it be culture, science, economics, etc. Global, general civilizational changes of the world mean that they concern every person. The global nature of modern processes covers not only humans, but also entire countries. Globalization can be seen as a movement towards rapprochement, integration, unity, the desire for openness. The higher education institutions are subject to globalization processes due to the fact they more than other types of education are included in the system of economic, political and cultural relations. Higher education is a guide for innovative ideas that promote the competitiveness of the national system. There is an interaction of educational systems and the interpenetration of educational ideas.

In addition, higher education, experiencing, along with all spheres of human existence, strong development of information technologies and a single information space, is characterized by global and regional interaction of knowledge flows. At the same time, the entire learning community is involved in a global change, as the global economy dictates its own conditions to global education systems.

Thus, globalization and its factors (economic-technological, political, cultural) affect education too. Its system transformation takes place, that is, the process of such (targeted and spontaneous) changes due to the influence of globalizing factors on it that cause it to acquire unique features.

According to experts, education is becoming one of the tools and resources of geopolitics (Kamashev et al., 2007: 132). Market economy requests change its priorities aimed at innovation, narrow specialization and professionalization.

The processes of modernization and transformation that have occurred within the entire society are also reflected in the education system of Russia. But the pace of positive changes in Russian society was reduced due to a system-wide crisis in the socio-economic sphere. Changes in values due to the increasing importance of higher education, the impossibility of implementing social mobility of young people, changing demand in the labor market towards its drop, a decline in living standards - all this has influenced social behavior and orientation of university graduates over the past decades.

The first half of the 1990s in Russia was marked by the introduction to the global information space. All means and types of mass media functioning in this space, created with the help of new technologies (multimedia, audio-visual communication media), have become the most important agents of the socialization of young people.

The change in social mobility, the transformation of the labor market and the overcoming of problems with employment, the adaptation processes that occur with university graduates in the changed socioeconomic conditions became possible in the changing socio-economic situation.

Crisis situations in various spheres of social life and in society as a whole exacerbate the problems of the socialization of young people, since they threaten the reproduction of both existing social structures and particular individuals and personalities. Under these conditions, the process of socialization and the factors that influence its success and, above all, education, become more relevant.

\section{Methods}

The activity, process, competence, system, information, socio-economic, axiological and other approaches that represent a set of generalized scientific statements on the problem under study, the characteristics of various areas of its research, the organization of theoretical and practical activities are defined as the methodological basis of socio-professional adaptation researcher (identifying the aspects necessary for 
studying, indicating the links between them, determining the direction of scientific research and the degree of transformation of the studied objects, etc.).

\section{Literature Review}

In modern science, the problem of professional socialization, the formation and development of the personality of a professional is studied by E.A. Klimov, A.K. Markova, S.V. Novikov, N.A. Perinskaia, O.V. Romashov, and V.D. Shadrikov.

V.N. Beznosikova, E.N. Kamysheva, R.P. Kolosova, T.L. Konchalina, V.S. Nemchenko, and N.V. Poliakova consider in their studies the specifics of the professional adaptation of young people. The process of professional development, the issues of training young engineers and technicians are covered by A.B. Kurlov, M.N. Rutkevich, G.A. Cherednichenko, V.N. Shubkina. Studies on specialized issues and areas of professional adaptation were conducted by E.V. Vitenberg, O.I. Zotov, I.K. Kriazheva, and L.M. Rastova.

Compared with the period of the late 1990s, in socio-economic and political stabilization of the social and public life of Russia, the labor motivation of young people changed. The need for professional growth (including career growth), professional development (self-improvement and self-expression) come to the fore. The role of professionalism as a driving force of positive social transformations, which is defined as a multicomponent phenomenon, increases, which entails an increase in the social activity of the individual and an increase in the responsibility of each person, both for the trajectory of their own development and for the successful implementation of the economic processes of the whole modern society.

Professionalization is considered as a process of mastering the necessary professional knowledge, competencies, as well as the ability to adapt to the professional environment. Professionalism is understood to mean the result of this process, an indicator of the success of its implementation, the qualitative characteristics of the employee.

At the beginning of the 21st century, the changed conditions of the socio-economic development of Russian society gave a qualitatively new sound to the process of professional socialization of a university graduate.

\section{Discussion}

A detailed consideration of the problems of socialization of the individual should focus on the influence of such a social institution as the institution of vocational education and on the process of socialization of the individual. The cognitive activity of students during their studies is eventually replaced by professional ones and entails a change in needs and interests, the selection of goals, and the methods and means for their achieving. To successfully introduce oneself to the professional environment, the student needs to master the ever-increasing amount of competencies.

The issue of classification of forms of professional socialization in the scientific literature is debatable and offers a wide variety of different points of view. Numerous classifications of forms of socialization are a consequence of the difference in criteria used as the basis for classifications: intentional and unintentional form, direct and indirect; directional and non-directional form, explicit and hidden; purposeful and spontaneous socialization.

Considering the forms of professional socialization, it is fair to talk about professional adaptation, integration and interiorization, understanding the latter as a process of borrowing certain information from the external environment, their assimilation as knowledge, skills, norms, behavior patterns, values and social adaptation (Rubchevskii, 2003). 
Being engaged in the study of the forms of professional socialization, S.P. Ivanenkov presented their classification based on the characteristics of the socialization environment. The scientist identifies three forms of socialization: real, social and informational (Ivanenkov, 2003), which show that the loss of the leading positions of the socializing role of traditional institutions of professional socialization has led to increase in the role of the social environment, evolving information flows, mass media, and electronic communication.

As the main forms of professional socialization L.E. Probst emphasizes professionalization and professional adaptation, which is one of the stages of professionalization (Probst, 2005).

Socialization, as many specialists argue, should be viewed as a two-way process: on the one hand, it is the assimilation by the individual of social experience by entering the social environment, the system of social ties; on the other hand, it is the process of active reproduction activities, inclusion in the social environment (Andreeva, 2001: 335). With this understanding of the specificity of socialization, professional self-determination of students can be represented as an awareness of their social significance in the process of work, assignment, along with human values, constituting the axiological core of professional activity. That is, professional socialization can be considered within a certain socioprofessional group and has a certain professional orientation.

Thus, we define professional socialization as a two-way process. One of its sides is the individual's entry into the professional life environment, his/her assimilation of social and professional experience, mastering of the standards and values of the professional community. The other side is the emphasis on the active realization of the accumulated cultural experience by the individual, when the adaptability of behavior is provided not by blindly submitting to external requirements, but by developing and making the choice of the optimal behavioral decision. Synthesis and complementarity of the identified opposites in the process of mastering a higher education program allow us to provide such an important characteristic of a future professional as competitiveness - the result of the implementation of higher education programs aimed at ensuring professional socialization of students.

In the modern vocational education, with an idle system of state distribution of specialists trained by educational institutions, the task of researching the professional adaptation of graduates of higher educational institutions is becoming urgent. Professional adaptation of university graduates in modern conditions is characterized by a complex structure, which is a unity not only of production, socioorganizational, socio-economic, but also socio-psychological, psychophysiological, and material and household adaptation (Terzi, 2009). This diversity of conditions and adaptation thereto is the factor that determines the interest of modern science in the professional adaptation of university graduates.

The requirements to university graduates posed by employers are updated every year, affecting the content and technological aspects of their professional training.

The process of social and professional adaptation involves both the development of direct professional duties and the inclusion of a person in the system of production relations within groups of specialists and the development of patterns of thinking and behavior that reflect the system of values and norms of the profession. Even at the stage of practice-oriented teaching of students, it is advisable to form their future readiness for social and professional adaptation, which generally contributes to the optimization of the adaptation process of graduates of higher educational institutions to the conditions of professional activity.

The phenomenon of social and professional adaptation is due to the fact that adaptation acts both as a process and as its result, which is noted by all researchers. As O.B. Tsypina notes, "the process of adaptation is the deployment of a phenomenon within a stage, the gradual and consistent quantitative 
accumulation of elements of adaptation, a certain combination of which leads to a more or less fixed transition to a new stage" (Tsypina, 2001). The result of the adaptation process, according to N.V. Terzi, is finding a vacant place (Terzi, 2009) for a university graduate, which would correspond to the level of education received, the content and nature of work, as well as the income.

At the same time, modern studies on the process of social and professional adaptation point out serious problems that employers recruit university graduates: as experts note, after recruiting young specialists, the duration of their professional socialization takes from three up to five months, which leads to significant financial losses for organizations. According to the estimates of every third employer, during a student's probationary period of the position, more than $30 \%$ of the specialist's potential labor return is lost (Borisova, 2012).

The results of studying students' opinions on the problem of professional socialization in terms of determining its role for students themselves are also interesting. Thus, in the course of a sociological survey of students at Southwestern State University, an absolute majority of respondents (95\%) note that the process of professional socialization occurs during training activities in educational organization (Kilimova, 2014: 118).

Social and professional adaptation of university graduates, which takes place in the context of modern modernization and restructuring of the economy, is complicated by the increase in the number of people receiving higher education, and, as a result, the tightening of conditions in the labor market and the problems of youth employment.

The main reason for the onset of the crisis at the stage of professional adaptation is the discrepancy between the real professional life and the beliefs of the university graduate about their employment. The incompatibility of the professional activity with the expectations explains the crisis, which is expressed in dissatisfaction with the content of work, its organization, official duties, production relations, working conditions and salary.

Considering university graduates as a specific category of labor in the labor market, we will focus on the characteristics of primary professional adaptation, which has certain stages and levels. Moreover, the organization of professional adaptation of university graduates as a special category of labor requires a special attitude and attention from the employer. Professional adaptation can go faster due to vocationaloriented training in the university, and those technologies aimed at creating simulation activities in the course of educational or practical training of students. It is advisable to introduce students into the work experience and official internships, which are found in organizations when hiring young professionals. Internship helps to identify the business qualities of a young specialist and contributes to the appropriate application of these qualities in production activities.

Successful professional adaptation is characterized by "the preservation and further development of proneness toward a particular professional activity, the merging of social and personal labor motivation, and is carried out in unity with social adaptation" (Kalugin, 1983: 71). The nature, pace and results of the adaptation of a young specialist depend on a number of factors, among which scientists name as the most significant: the factor of the environment in which the adaptation takes place; factors that can be called individually-personal, that is, associated with the characteristics of the adaptable; management factors of adaptation.

Thus, an important criterion for adaptation as a dynamic equilibrium in the "person-professional environment" system is first of all the efficiency of activity. Effective activity is characterized by high productivity and product quality, optimal energy and neuro-psychological costs, professional satisfaction. Such qualities are formed in the course of social and professional adaptation, which require a specialist to 
have such competencies that, in the face of changes in the professional environment, contribute to the ability to quickly adapt to the realities and demands of the labor market.

\section{Conclusion}

In the course of the study, the socio-economic conditions of modern Russian society were identified, determining the professional socialization of a university graduate. Since the process of professional adaptation is a sociocultural phenomenon due to the globalization of modern education and its changing priorities aimed at innovation, narrow specialization and professionalization, the preparation of a university graduate must take into account this specificity. In addition, the economic and technological factor, determining the transformation of the economy from a closed type to open forms and creating a single economic space, also leads to significant changes in the system of higher education itself. In modern conditions of society and work, a young specialist, a university graduate must have the ability to quickly adapt to the variability of social conditions of life, the ability to respond flexibly to contemporary challenges is necessary. Such skills, predetermined by professional socialization, should be formed by a university student in the system of professional training and developed by a young specialist during the period of social and professional adaptation.

One of the problems of studying the socio-professional adaptation of a university graduate is the definition of its phenomenon in the structure of the adaptation process in general. Socio-professional adaptation of young specialists in modern conditions is associated with their employment, which appears to modern university education one of the criteria for the effectiveness of work on training bachelors. Employment launches the process of adaptation of a university graduate to modern conditions of the labor market, as a result of which mastering of professional and personal qualities takes place in order to increase competitiveness in constantly changing production conditions.

\section{References}

Andreeva, G. M. (2001). Social psychology: a textbook for higher education institutions. Moscow: Aspekt Press. URL: http://elibrary.bsu.az/books_163\%5CN_5.pdf

Borisova, A. A. (2012). Quality of professional training in labor management: expert opinion. Management of Economic Systems: Electronic Scientific Journal, 6.

Ivanenkov, S. P. (2003). Problems of socialization of modern youth. St. Petersburg: Sintez-Poligraph.

Kamashev, S. V.; Mikhalina, O. A. \& Nalivaiko, N. V. (2007). Actual problems of security of the national education system. Novosibirsk: Publishing House of the Siberian Branch of the Russian Academy of Sciences.

Kilimova, L. V. \& Fedosov, I. A. (2014). Professional socialization of students of the South Ural State University in the context of modernization of the system of higher professional education. Proceedings of the South-West University. Ser. Economy. Sociology. Management, 4, 114-122. 
Probst, L. E. (2005). Professional socialization of school youth in modern Russia. Author's absract, MD Sociology.

Rubchevskii, K. V. (2003). Socialization of the personality: interiorization and social adaptation. Social Sciences and Modernity, 3, 147-51.

Terzi, N. V. (2009). Professional adaptation of university graduates in modern conditions. Author's abstract, PhD Thesis on Economics. Moscow: Publishing House of National Scientific Research Educational Institution of Higher Professional Education "Moscow Humanitarian University". URL: http://www.mosgu.ru/nauchnaya/publications/2009/abstracts/Terzi_NV.pdf

Tsypina, O. B. (2001). Socio-professional adaptation of university graduates: Regional aspect. Author's abstract, PhD Thesis on Sociology. Penza: Penza State University. 